\title{
Pensamento histórico de jovens sobre "gênero" a partir da revista Capricho (2005-2006)
}

\author{
Youth historical thinking about "gender" from the Capricho \\ magazine (2005-2006).
}

\author{
Flávia Mantovani*
}

\section{RESUMO}

Objetiva-se investigar a o pensamento histórico de jovens sobre "gênero", a partir da revista Capricho (abr/2005-mar/2006), utilizando-a como uma fonte histórica. Interessa observar se construíram uma "literacia histórica" e se a mobilizam nas suas práticas de leitura, considerando tal literacia como um modo de ler e interpretar o mundo historicamente. A apreensão destas ideias deu-se através de uma prática didático-pedagógica, pautada no uso escolar de fontes históricas, na qual se analisa a "literacia histórica" de estudantes do segundo ano "A" do Ensino Médio do Colégio de Aplicação - Londrina/PR, em relação a esta revista. Utilizou-se a técnica de grupos focais interposta aos pressupostos da aula-oficina, buscando desenvolver uma interpretação/leitura das fontes e sua compreensão contextualizada. Em três aulas gravadas e transcritas, coletou-se ideias prévias de estudantes e suas interpretações da fonte, através da qual trabalha-se a construção de uma literacia histórica. É necessária uma problematização e análise, na perspectiva histórica, deste sujeito o qual se pesquisa, os/as estudantes do "2ํㄱ", sob o pressuposto de que a adolescência é uma construção discursiva e um fenômenos cultural, ou seja, problematiza-se este grupo de sujeitos, adolescentes, de modo a desnaturalizá-los. Assim, aborda-se as relações destes jovens com a questão de gênero, tomando o espaço escolar como importante na construção desta relação e, ainda, na produção das diferenças. Em um segundo momento, discute-se a revista Capricho e as várias dimensões que assume nesta pesquisa, isto é, como um produto da cultura midiática que pede uma avaliação que abarque, inclusive, a dimensão da sua apropriação, ou ainda, dos usos e interpretações dos estudantes. A escolha do recorte temporal deu-se em função da existência de um padrão editorial em relação à identidade da jovem: as edições analisadas evidenciam a preocupação com uma dada autenticidade da leitora, através do slogan "seja diferente, seja você". Também, a revista Capricho é entendida como fonte histórica utilizada em contexto escolar. Apoiados em referenciais do campo da História e da Comunicação, entende-se a relação entre Capricho e leitoras em sua

\footnotetext{
* Mestre em História Social pelo Programa de Pós-Graduação em História Social - Universidade Estadual de Londrina - UEL, 2014.
} 
complexidade, ambas constroem uma a outra recursivamente, são interdependentes. A partir desta ideia, é possível pensar e problematizar não apenas a mídia enquanto produtora de pedagogias de gênero, mas também a o público enquanto um co-produtor da revista, já que esta se apropria dos seus códigos culturais, a fim de não destoar do horizonte de expectativas de suas leitoras. Enfim, apoia-se em referenciais do campo investigativo da Educação Histórica, onde se procura investigar, também, como se dá o aprendizado histórico dos sujeitos. Ainda, utiliza-se o conceito de "literacia histórica" cunhado por Peter Lee, em uma análise das falas de alunos sobre questões de gênero e sexualidade na Capricho. Percebeu-se que os alunos já trazem ideias e noções sobre gênero e que tais ideias reproduzem, em certa medida, uma concepção conservadora. Entretanto, demonstram capacidade de observar e historicizar as questões de gênero que a Capricho traz, lendo-a como uma fonte histórica, ou seja, contextualizando seus discursos, o que significa uma "literacia histórica".

Palavras-chave: literacia histórica; Revista Capricho; cultura midiática; ensino de história e gênero.

\section{RESUMEN}

El objetivo es investigar el pensamiento histórico de jóvenes sobre el "género" tomando como punto de partida la revista Capricho (abr/2005-mar/2006), la utilizando como una fuente histórica. Interesa observar si construyeron una "alfabetización histórica" y la movilizan en sus prácticas de lectura, considerando la alfabetización histórica la como una manera de leer e interpretar el mundo históricamente. La aprehensión de las ideas ha ocurrido a través de una práctica didáctica y pedagógica, basada en el uso de la las fuentes históricas en contexto escolar, en el que examina la "alfabetización histórica" con respecto a Capricho, de los estudiantes del segundo año "A" de la escuela secundaria "Colégio de Aplicação" - Londrina/PR. Se utilizó la técnica de grupos focales superpuesta a la propuesta del clase-taller, desenvolviendo la interpretación/lectura de las fuentes y su comprensión contextual. En tres clases grabadas y transcritas, se recogió ideas las ideas previas de los alumnos y sus interpretaciones de la fuente, a través del cual trabaja para construir una alfabetización histórica. Es necesario una problematización y el análisis, desde una perspectiva histórica, de este sujeto el cual se estudia, los/las estudiantes del "2ํㅡ" fenómeno cultural, en otras palabras, problematiza este grupo de sujetos, los adolescentes, con el fin de desnaturalizar ellos. El enfoque es las relaciones de estos jóvenes con las cuestiones de género, tomando la escuela como importante en la construcción de esta relación y también la producción de diferencias. En un segundo paso, se discute la revista Capricho y las diversas dimensiones que asume esta investigación, es decir, como un producto de la cultura mediática que aboga por una revisión que abarca, incluyendo la extensión de su apropiación, o, los usos y interpretaciones de los estudiantes. La elección del marco de tiempo ocurrió debido a la existencia de normas editoriales relativas a la identidad de los jóvenes: las revistas analizadas demuestran la preocupación por una autenticidad dada del lector, a través del lema "Sé diferente, ser tú."Además, la revista Capricho es entendida como una fuente histórica utilizada en el contexto escolar. Apoyado en referenciales de la Historia y de la Comunicación, si piensa la relación entre los lectores y Capricho en su complejidad, se construye una a la otra, de forma recursiva, son 
interdependientes. A partir de esta idea, es posible pensar y cuestionar no sólo los medios de comunicación como productores de las pedagogías de género, sino al público como co-productor de la revista, ya que se apropia de sus códigos culturales, a fin de no entrar en conflicto con las expectativas de sus lectores. De todos modos, se basa en las referencias del campo de investigativo de la Educación Histórica donde también pretende investigar cómo es el aprendizaje del sujeto acerca de la historia. También utiliza el concepto de "alfabetización histórica" acuñado por Peter Lee, en un análisis del discurso de los estudiantes en temas de género y sexualidad en la Capricho. Se observó que los estudiantes ya traen ideas y nociones sobre el género y que tales ideas se reproducen, en cierta medida, un diseño conservador. Sin embargo, demostran la capacidad de observar y ubicar históricamente las cuestiones de género que trae Capricho, la leendo como fuente histórica, es decir, la contextualización de sus discursos, lo que significa una "alfabetización histórica".

Palabras-clave: William Blake. La religiosidad. La sociedad industrial. Literatura. Romanticismo. 